\title{
Aprendiendo de la pseudociencia ${ }^{1}$ \\ Learning from the pseudoscience
}

\author{
ANDRÉS CARMONA CAMPO \\ IES Hermógenes Rodríguez. (España)
}

recibido: 01.07.2015

aceptado: 24.07 .2015

\section{RESUMEN}

El pensamiento crítico y escéptico hacia las pseudociencias se ha movido tradicionalmente en un sentido excesivamente racionalista. En el texto se critica ese exceso de racionalismo para adecuarlo a las recientes investigaciones en neurociencia, psicología y economía conductual acerca de las emociones y la toma de decisiones. Desde esta perspectiva, se intenta explicar la pervivencia de las pseudociencias pese a la crítica escéptica, y apuntar alternativas para hacer más eficaz y eficiente la difusión del pensamiento crítico y científico.

\section{PALABRAS CLAVE \\ CIENCIA, PSEUDOCIENCIA, EDUCACIÓN, ESCEPTICISMO, PENSAMIENTO CRÍTICO}

\begin{abstract}
Skeptical and critical thinking to the pseudoscience has traditionally moved in an overly rationalistic sense. The text criticizes that excess of rationalism to adapt it to recent research in neuroscience, psychology and behavioral economics about the emotions and decision-making. From this perspective, tries to explain the persistence of the pseudoscience despite skeptical critique, and target alternatives to make more effective and efficient dissemination of scientific and critical thinking.
\end{abstract}

Claridades. Revista de filosofía 7 (2015), pp. 31-43

ISSN: 1889-6855 ISSN-e: 1989-3787 Dl.: PM 1131-2009

Asociación para la promoción de la Filosofía y la Cultura (FICUM)

\footnotetext{
${ }^{1}$ Un borrador de este texto apareció por primera vez en el blog Filosofía en la Red el 28/03/2015. El texto que aquí se ofrece es una nueva versión corregida y revisada. (http://www.filosofiaenlared.com/2015/03/aprendiendo-de-la-pseudociencia-andres.html)
} 


\section{KEYWORDS \\ SCIENCE, PSEUDOSCIENCE, EDUCATION, SKEPTICISM, CRITICAL THINKING.}

\section{INTRODUCCIÓN}

La homeopatía es falsa. Y punto. Científicamente hablando no hay más que decir. No hay debate sobre esto. Se han dado mil argumentos ${ }^{2}$ pero hay uno, para mí, contundente: no hay anticonceptivos homeopáticos. Cuando una sustancia se diluye infinitesimalmente desaparece hasta la última molécula y lo que queda es agua pura y cristalina. Cuando una píldora de azúcar se moja en esa agua no resulta un medicamento, resulta lo que es: azúcar y agua. Ya está.

¿Ya está? Si es así de simple, ¿por qué la homeopatía "funciona"? ¿Por qué tanta gente la sigue tomando? ¿Cómo es que resulta un negocio multimillonario? ¿Tanta gente puede estar equivocada?

¿No será que estamos enfocando mal el asunto? Vamos a ensayar esta hipótesis: la crítica científica y escéptica a la homeopatía, y otras pseudociencias $^{3}$, posiblemente esté cometiendo un acierto y un error en su crítica. El acierto son los contundentes argumentos que desmontan las afirmaciones extraordinarias de esas pseudociencias: a la memoria del agua, por ejemplo. El fallo es la falta de alternativa y la incomprensión de lo que realmente busca alguien cuando acude a la homeopatía o a otra falsedad semejante.

Richard Wiseman también es psicólogo y también es escéptico. En su libro ¿Es esto paranormal? (2011), Wiseman cuenta cómo su encuentro con Susan Blackmore cambió su perspectiva hacia los fenómenos paranormales. No cambió su escepticismo hacia esos "fenómenos", sino su forma de acercarse a ellos:

“[Blackmore] explicó que, en vez de examinar si tales fenómenos [paranormales] eran o no auténticos, ella consideraba que valía más la pena investigar por qué la gente experimenta estas extrañas sensaciones (...)

\footnotetext{
2 Para una crítica exhaustiva de la homeopatía, véase Sanz, 2010.

${ }^{3}$ En este texto se utilizan a menudo términos como "ciencia", "pseudociencia", "escepticismo" que no es cuestión de definir por su complejidad y para ceñirse al espacio de un texto como este. El sentido en el que el autor entiende esos términos y sus relaciones con otros como "religión", "creencias", "conocimiento", etc., puede consultarse en Carmona, 2013a).
}

Claridades. Revista de filosofía 7 (2015) 
los comentarios de Sue me hicieron caer en la cuenta de que tal trabajo podría merecer la pena si me distanciaba de la existencia de los fenómenos en sí mismos y, en cambio, me centraba en la oculta y fascinante psicología que había detrás de las creencias y experiencias de la gente" (Wiseman, 2011: 14-15).

Tal vez el problema sea de enfoque, como indica Wiseman. El escepticismo ha minado todas las bases de las pseudociencias. Hoy día ya no hay debate científico sobre la parapsicología, los OVNIs, la homeopatía, o las vacunas. No son temas en los que la comunidad científica esté dividida fifty-fifty a favor y en contra. Sin embargo, ese consenso científico no tiene reflejo en la sociedad: mucha gente todavía cree en el mito del 10\% de la mente, en la existencia de OVNIs, en la memoria del agua o en conspiraciones para vacunarnos en contra de nuestra salud ${ }^{4}$. Esto sí que es un auténtico misterio para el escepticismo científico. Pero un misterio con solución que viene de la mano de la neurociencia, la psicología evolutiva y la economía conductual. En definitiva, de la ciencia. Como tantas veces, la ciencia se critica a sí misma y así va aumentando el conocimiento.

\section{EL ERROR DEL ENFOQUE DEL ESCEPTICISMO CIENTÍFICO}

El escepticismo científico ha pecado en su enfoque de excesivamente racionalista. Su esquema subyacente ha sido el siguiente:

La explicación verdadera, si es comprendida, conduce a la creencia verdadera. Si ante una explicación verdadera, no se produce una creencia verdadera, eso es que esa persona no ha comprendido la explicación. Entonces es que esa persona es estúpida y por eso no la comprende.

Durante mucho tiempo, el escepticismo ha creído que la causa del éxito de la pseudociencia era la ignorancia: en una línea ilustrada, se pensaba que, aumentando el conocimiento, disminuiría la pseudociencia. Y eso es cierto en parte, pero falta algo más. Siendo necesario, no es sufi-

\footnotetext{
${ }^{4}$ Esta última conspiranoia ha resultado fatalmente grave hace muy poco: el 27 de junio de 2015 moría en el hospital Vall d'Hebron de Barcelona un menor de seis años infectado de difteria, el primer caso desde 1987 en España. El niño no estaba vacunado debido a las creencias anti-vacunas de sus padres. Véase el diario El País del 2 de junio de 2015

(http://ccaa.elpais.com/ccaa/2015/06/02/catalunya/1433255972_743084.html) y del 27 de junio (http://ccaa.elpais.com/ccaa/2015/06/27/catalunya/1435393852_158995.html).
} 
ciente. Ahí ha estado el fallo: el escepticismo ha dado demasiado por supuesto que sí era suficiente. Por eso, el escepticismo organizado ${ }^{5}$ ha dedicado sus fuerzas principalmente al desenmascaramiento de las pseudociencias, mostrando sus falacias, sus errores científicos, sus absurdos y sus aspectos más ridículos y también más peligrosos. Se creía, de un modo que ahora con más perspectiva podemos considerar como bastante ingenuo o demasiado optimista, que eso bastaría para acabar con las creencias pseudocientíficas.

\section{III. ¿QUÉ OFRECEN LAS PSEUDOCIENCIAS?}

Cierto es que las pseudociencias cambian, porque también en esto hay modas. En el siglo XIX fue el espiritismo, en la segunda mitad del XX la ufología y la parapsicología, y ahora mismo las pseudomedicinas llamadas "naturales" o "alternativas". Pero la esencia viene a ser la misma. Y tal vez indagando en esa esencia podamos encontrar la clave su éxito: ¿qué ofrecen esas pseudociencias y por qué no basta la crítica racionalista contra ellas?

Para empezar, hay que tener en cuenta que nuestro cerebro no está evolutivamente preparado para la verdad sino para la supervivencia, y más exactamente, para el éxito reproductivo (Wilson, 1991; Dawkins, 2002; Pinker, 2008). Nuestro cerebro busca la verdad en función de la supervivencia, de ahí que pueda sacrificar la primera por la segunda si hace falta. Un ejemplo son las ilusiones ópticas: nuestro cerebro nos engaña para poder percibir de forma tridimensional. O el fenómeno de la paraeidolia: la tendencia a percibir caras en donde no las hay, y que deriva de nuestra habilidad evolutiva para reconocer las caras de las personas. Pero también hay ilusiones cognitivas y emocionales (Gilbert, 2006). Nuestro cerebro modifica y falsea la forma de comprender y sentir la realidad para adaptarnos y sobrevivir si es necesario.

A partir de lo anterior puede resultar más fácil entender ciertos fenómenos. Por ejemplo, que las personas no hacemos análisis racionales previos a la hora de tomar determinadas decisiones, sino que normal-

\footnotetext{
${ }^{5}$ Entendemos por escepticismo organizado al que desarrollan asociaciones con el fin concreto de difundir el pensamiento crítico y escéptico y la crítica de la pseudociencias. El referente en EEUU sería el Committee for the Scientific Investigation of Claims of the Paranormal (CSICOP) (http://www.csicop.org/) y en España la asociación ARPSociedad para el Avance del Pensamiento Crítico (www.escepticos.es).
}

Claridades. Revista de filosofía 7 (2015) 
mente tomamos la decisión de forma emocional y después la justificamos racionalmente a posteriori. Nuestro cerebro funciona más como un abogado que como un juez: no analiza los argumentos y pruebas a favor y en contra y luego decide de forma imparcial en función del peso de unos y otros, sino que toma partido previo y después intenta argumentar y busca las pruebas a favor de la decisión que ya ha tomado (Gilbert, 2006; Haidt, 2012, Ariely, 2013). Por tanto, la crítica racionalista tiene aquí poco que hacer. Si alguien ha tomado una decisión emocional a favor de la homeopatía, por ejemplo, de nada valdrán todos los argumentos racionales en contra, en más, pueden servir justo para lo contrario: para reafirmarle en sus creencias.

Otro ejemplo es la economía. El modelo estándar de economía se basa en lo que se conoce como el homo oeconomicus. Según este modelo, los sujetos son agentes racionales que sopesan pros y contras y eligen la mejor opción en función de la información disponible (la mejor opción en términos de sus preferencias, intereses o utilidades). Sin embargo, el modelo no funciona empíricamente, a pesar de su corrección matemática. Tanto en los experimentos como en la vida real, los sujetos no se ajustan a las predicciones del modelo. Los sujetos acaban tomando decisiones en contra de sus propios intereses o que no son las que los maximizan como cabría esperar (Kahneman, 2013).

Para explicar lo anterior, podemos hacer una analogía con la física. Según el modelo de la física, una pluma y un martillo deben caer al mismo tiempo a la Tierra. Pero, si los dejamos caer, no sucede así: el martillo cae antes. Hay una explicación, claro: la resistencia del aire. Una pluma y un martillo caerán al mismo tiempo, si no hay resistencia del aire. El pobre Galileo nunca pudo comprobarlo por sí mismo, a lo más que pudo acercarse fue a dejar rodar bolas de diferentes masas en un plano inclinado. Más de 300 años después, en 1971, el astronauta David Scott pudo realizar el experimento sin resistencia del aire, en la luna, y dedicárselo a Galileo.

El modelo de la economía estándar, y el modelo de crítica escéptica a la pseudociencia, no es que estén equivocados, lo que pasa es que ignoran "la resistencia del aire". Funcionarían a la perfección "en la luna", pero no en nuestro mundo. Aquí en la tierra la "resistencia del aire" son todos los demás factores que intervienen en la conducta humana y en nuestras creencias. El conocimiento científico es uno de esos elementos, pero no es el único ni muchas veces el principal. Nuestro pasado evolu- 
tivo, las emociones y otras variables también juegan su papel y hacen las veces de "resistencia del aire" que estropea el modelo puramente racionalista. En ese sentido, la economía conductual se ha propuesto tener todo eso en cuenta y ha elaborado otros modelos que se ajustan más y mejor a la conducta real de los individuos. De esta forma, contraponen al bomo oeconomicus de la teoría estándar con el ser humano de carne y hueso, a los que Daniel Kahneman ha llamado el econo y el bumano respectivamente (Kahneman, 2013).

Lo que habrá que analizar, entonces, es qué ofrece o qué consiguen las pseudociencias que las hacen tan sumamente atractivas y exitosas incluso entre la gente inteligente, y que hace las veces de "resistencia del aire". No se trata de dar la respuesta definitiva en estas líneas, porque requeriría de investigación empírica, pero sí podemos lanzar alguna hipótesis que pueda señalar en ese sentido.

A veces se ha señalado que las pseudociencias ofrecen consuelo y que, aunque sea falso, es lo que las hace tan atractivas. Ante el aparente sinsentido de la vida, las pseudociencias afirman una vida después de la muerte, o la comunicación con ese más allá, o el remedio para las enfermedades incurables. Puede ser, pero no es solo eso, o dicho de otra forma, las pseudociencias ofrecen ciertamente consuelo, pero ofrecen algo más que es lo que produce ese consuelo y otras cosas.

Uno de los fallos de la crítica escéptica, y a la vez acierto de la pseudociencia, es que aquella crítica es negativa, demoledora, deconstructiva, pero esta es positiva, constructiva. La pseudociencia no desmonta la ciencia, de hecho intenta presentarse como científica. Pero hace algo más: ofrecer una alternativa en positivo, algo a lo que agarrarse. El espiritista hace creer al viudo que puede hablar con su esposa fallecida, el escéptico le demuestra que eso es imposible. El homeópata hace creer que una pastilla de azúcar cura una enfermedad, el escéptico demuestra que no puede ser. La pseudociencia ofrece algo, el escepticismo lo destroza. La diferencia es que la pseudociencia resulta más agradable, porque por lo menos ofrece algo, aunque sea ficticio o ilusorio. Pero aún así, tiene fuerza, aunque solo sea la potencia del efecto placebo, que ya es mejor que nada, y que sabemos que es sumamente poderosa. El placebo activa la segregación de dopamina y puede ser sumamente útil, sobre todo si no hay otra cosa mejor. Y es que, en este caso, no vale más "solo que mal acompañado": es preferible la compañía de la pseudociencia que la soledad del escepticismo.

Claridades. Revista de filosofía 7 (2015) 
El escepticismo es negativo hasta en su nombre: escéptico es quien duda, quien sospecha. Pero nuestro cerebro no se maneja con el lenguaje negativo. Ya sabemos que es imposible cumplir la orden de: "No pienses en un elefante rosa". El mensaje en positivo (aunque sin pretenderlo conscientemente) que transmite el escepticismo es la resignación. Viene a decir: tu enfermedad no tiene cura, resígnate; tu padre ha muerto para siempre, resígnate; no hay vida inteligente en nuestra galaxia y puede que en ninguna más, resígnate. Por eso la pseudociencia parece tener esa aura de rebeldía, de inconformismo, de resistencia ante la resignación. Es como si la pseudociencia hiciera suyo el lema de: "Sed realistas, pedid lo imposible" (y tal vez por eso sea tan atractiva para cierta izquierda políti$\left.\mathrm{ca}^{6}\right)$.

Eso es algo que hay que aprender de la pseudociencia. La ciencia y el escepticismo deben superar su aspecto negativo hacia la oferta en positivo. El mensaje no puede ser de resignación sino de rebeldía. Y además la ciencia cuenta para eso con una baza poderosísima: lo que puede ofrecer es auténtico y no falso como la pseudociencia. Para entenderlo mejor veamos primero algo más qué es lo principal que ofrece la pseudociencia.

Gran parte de quienes acuden a la pseudociencia lo hacen "rebotados". No se lanzaron de cabeza a la homeopatía o la acupuntura, por ejemplo, sino que primero probaron con la ciencia convencional. Pero ¿por qué salieron rebotados? En realidad, lo asombroso no es que algunos hagan eso, sino por qué no lo hace más gente aún. Recordemos cómo son las consultas de los hospitales en general. Frías, rápidas y distantes. Mucho tiempo en largas colas de espera para unos escasos minutos de preguntas, observación y receta. Inevitable sensación de ser un número, uno más, despersonalización. Uno siente que es un coche y el médico un mecánico. En cambio, ¿qué ofrece, principalmente, la pseudociencia? Atención personalizada. Esa es la clave. Lo demás es lo de menos. Da igual si esa atención personalizada la hace mirándonos el iris (iridología), estimulando los chakras o haciendo imposición de manos (reiki). Lo importante es que nos hacen sentirnos únicos, especiales y valiosos. De hecho, la parte más importante, y tal vez menos estudiada por la crítica escéptica, es el trato del pseudoterapeuta (o del médium, o del tarotista) con el cliente. El escepticismo se ha centrado demasiado en criticar sus métodos (la ouija, las mesas giratorias, la dilución en serie...) y

\footnotetext{
${ }^{6}$ Sobre las relaciones entre pseudociencia e izquierda política, véase Carmona, 2013b.
} 
no tanto en ese trato personal y personalizado. Cuando se ha hecho, no se ha enfocado correctamente. Siempre se ha considerado de un modo más o menos despectivo, diciendo que se trata de personas más bien débiles que necesitan consuelo y que acuden a la pseudociencia por eso. $\mathrm{Y}$ es cierto en muchos casos, pero no hace falta ser débil para eso necesariamente. Todo el mundo quiere que le traten de esa forma. Todos queremos sentirnos únicos y especiales, y la pseudociencia consigue que nos sintamos así. Igual que lo consigue el amor: la enorme fuerza del amor deriva en parte de ese sentimiento de ser especiales para alguien, y todos nos sentiríamos muy frustrados si nuestras parejas nos dijeran que nos eligieron al azar, por ejemplo. Y no somos débiles por eso.

Todas las consultas de pseudomedicina alternativa dedican mucho tiempo al paciente. El falso terapeuta conoce a cada uno de sus clientes, les llama por su nombre, les recuerda, sabe su historia personal o les pide que se la cuenten, les deja desahogarse, les escucha, les sonríe, les entiende, va más allá de los síntomas, quiere ir a la causa "profunda". No es nuevo, el psicoanálisis ya hacía todo esto. Siguiendo con la analogía del amor: la pseudociencia es a la ciencia lo que el amante al matrimonio. Cuando en la pareja el amor deja paso al cariño, el romance a la rutina, las risas a las discusiones o el aburrimiento, entonces el amante ofrece lo que falta en el matrimonio: aventura, emociones y, sobre todo, trato personal y especial. El amante hace sentir a la otra persona que es única, que es fantástica, que es genial. Mientras que la pareja no le hace sentir nada de eso. Todo lo demás, en el fondo, da igual. No importa el medio con el que el amante lo haga, siempre que logre que la otra persona se sienta especial y única: basta una mirada cómplice, un mensaje, una llamada de teléfono muy corta. El escéptico podría decir: "Pero si es solo una mirada, si es solo un mensaje, si es solo una llamada. ¿Qué es eso comparado con la estabilidad matrimonial, con la tranquilidad económica del matrimonio, con la casa en común compartida?" Pero ¡con qué ansiedad se busca esa mirada, con qué emoción se mira el mensaje del teléfono, con qué nervios se espera la llamada! Y con qué indiferencia que percibe todo lo demás del matrimonio. Es que no es solo eso. ¿Que la conducta no es racional? Por supuesto: en términos estrechamente racionalistas no lo es, pero ampliando el concepto de racionalidad para incluir todo lo que la neurociencia nos enseña del cerebro, todo lo que la psicología evolutiva nos muestra, y todo lo que la economía conductual nos señala, entonces sí que lo es, iy mucho! El escéptico cónyuge podría decirle a su pareja

Claridades. Revista de filosofía 7 (2015) 
que el amante es un don nadie, que no tiene donde caerse muerto, que es flor de un día. Y no le faltará razón. Pero su pareja seguirá enamorada de la otra persona: porque le ofrece algo que el cónyuge no le da.

Las religiones ${ }^{7}$ y las sectas llevan siglos explotando la ilusión de sentirse especiales. Los creyentes se consideran a sí mismos elegidos por Dios o los extraterrestres. Creen que el ser más grande del universo se ha fijado precisamente en ellos para darles una revelación y salvarles. Piensan que seres inteligentes de otros planetas han recorrido miles de años luz solo para decirles a ellos que la paz en el mundo es una buena idea. La misma idea subyace en las teorías de la conspiración. El conspiranoico se siente alguien especial porque sabe secretos ocultos sobre el gobierno del mundo que nadie más conoce y de los que él, misteriosamente, ha podido enterarse: el orden mundial illuminati, el origen reptiliano de los gobernantes, los hilos judeo-masónicos de la economía global...

La necesidad de sentirse únicos y especiales es universal. Lo demuestra el efecto Forer-Barnum (Wiseman, 2008: 37-43) y es la clave de los horóscopos y las consultas de los médiums y del tarot. Un mensaje deliberadamente ambiguo y generalista es interpretado por cada sujeto de un modo totalmente íntimo y personal. En los experimentos, se entrega una descripción "personalizada" del sujeto (a través de un análisis grafológico, astrológico o como sea) y se le pide valorar hasta qué punto es acertado. Los sujetos puntúan con 8 o 9 en una escala de 0 a 10. En realidad, se les ha entregado exactamente la misma descripción a todos. ¿Por qué ocurre? Porque todos queremos sentirnos distintos y especiales. Justo lo contrario de lo que nos hace sentirnos el médico en el hospital o el maestro en la escuela. Ahí somos uno más, un expediente.

\section{IV. ¿QUÉ PODEMOS APRENDER DE LA PSEUDOCIENCIA?}

¿Qué podemos aprender aquí de la pseudociencia? A tener en cuenta esa necesidad de empatía, de trato personal y personalizado. En sanidad, por ejemplo. Si los médicos de la Seguridad Social pudieran dedicar el mismo tiempo, y de la misma forma empática y personalizada al máximo,

\footnotetext{
${ }^{7}$ Qué relaciones haya entre la religión, la ciencia y la pseudociencia es un asunto complejo y polémico. Desde el punto de vista del autor, y en la línea de otros como Alan Sokal (Sokal, 2009: 461 y ss), la religión puede ser una pseudociencia como cualquier otra en tanto que haga como ellas: hacer afirmaciones extraordinarias sin suficiente apoyo empírico o en contra del establecido por el consenso científico del momento.
}

Claridades. Revista de filosofía 7 (2015) 
como hacen los homeópatas, nadie cambiaría el instrumental científico del médico por las pastillas de azúcar del homeópata. La medicina convencional debe aprender eso de la pseudomedicina. No se trata de incluir en la sanidad pública la homeopatía, la acupuntura, el reiki o las flores de Bach, pero tampoco tiremos al niño con el agua sucia (aunque esté dilui$\mathrm{da})$.

Para eso hacen falta, por lo menos, dos cosas: formación y medios. La formación de todo el personal sanitario (médicos, enfermeros, etc.), debería incluir, además de todos los contenidos puramente académicos, una parte de formación en esa atención personal tomados de la psicología científica. Deberían formarse en todo lo que la neurociencia y la psicología nos enseñan de las emociones y que las pseudociencias utilizan intuitivamente, sin caer en las falacias de la autoayuda, el pensamiento positivo, el coaching, la PNL y otras pseudociencias similares ahora en boga (Ehrenreich, 2012; Delgado, 2014).

En segundo lugar hacen falta medios materiales. El homeópata (o el médico privado) pueden dar ese trato porque su ratio médico-pacientes es infinitamente más reducida que la del médico público. No es lo mismo atender a unos cuantos pacientes que atender a cientos. Debemos conseguir reducir esa ratio en la sanidad pública formando a más médicos y que cada uno atienda a menos pacientes. Que los conozca, que sepa sus nombres y su historial sin mirar los expedientes, que les escuche, que les dé consejos, que pueda detectar rápidamente que su dolor de espalda se debe a sus discusiones de pareja o al estrés de no encontrar trabajo, por ejemplo. Que pueda dedicar una hora a cada uno, tranquilamente, sin prisas, sin colas de espera. Por no hablar de la congestión de los hospitales públicos, de las camillas con enfermos en los pasillos, o el mero hecho de que no haya habitaciones individuales para los pacientes, que ya sería bastante. La sanidad privada lo consigue: poniendo un precio alto por consulta. Dejando fuera de una sanidad de científica y de calidad a la inmensa mayoría de la población, o echándola en manos de homeópatas, acupuntores o curanderos.

Lo mismo puede decirse de la educación pública. Las escuelas pseudocientíficas también empiezan a proliferar, igual que el homeschooling. Por ejemplo, las escuelas basadas en los métodos pseudocientíficos del esoterismo de la teosofía, como son las escuelas Waldorf. Cada vez más familias reniegan de la enseñanza tradicional por lo mismo que hemos dicho antes de la medicina: es fría, distante, impersonal, y muchas veces ni si- 
quiera logra sus objetivos (por ejemplo, nuestros jóvenes pasan más de diez años estudiando inglés en primaria, secundaria y bachillerato, y salen sin saberlo correctamente). Resulta imprescindible lo mismo que hemos dicho: formación y medios. Hay que formar a los futuros profesores ( $\mathrm{y}$ reciclar a los actuales) en otra forma de enseñanza, en otra metodología, en otra forma de relacionarse con el alumnado y las familias, mucho más individualizada, personalizada, donde puedan detectarse las carencias y las potencialidades de cada alumno particularmente, para remediar las primeras y fomentar las segundas. Para eso hay que darles medios adecuados: para empezar, aulas con menos alumnos por profesor.

Para ir terminando, no solo en medicina y educación hace falta este cambio de orientación en la crítica escéptica y científica de la pseudociencia. En general, el enfoque y el discurso crítico hacia la pseudociencia debe cambiar en un sentido positivo. Siguiendo el ejemplo de Carl Sagan. Leer su obra no es solo un placer estético y una fuente de conocimiento, es contagiarse de su pasión por la ciencia y por comprender de un modo auténtico cómo es el mundo en el que vivimos. Su mensaje es positivo: la realidad es apasionante, investigarla y entenderla es una satisfacción en sí misma. Las cosas tal y como son tienen de por sí una belleza y una grandiosidad que no hace falta adornarlas con misterios esotéricos para hacerlas más interesantes.

La ciencia no es valiosa solo en su aspecto práctico como tecnología que nos facilita el día a día. La ciencia es valiosa de por sí como fuente de conocimiento, de placer y como forma de vida, como actitud ante los problemas. La perspectiva científica no es contraria a las emociones porque las comprende y las integra. No hace falta ningún dios para sentirse especiales ni afortunados: la teoría de la evolución nos enseña que el mero hecho de haber nacido y seguir vivos es ya un milagro natural. Pensemos que para que cada uno de nosotros esté aquí, todos nuestros antepasados, desde hace miles de años, tuvieron que sobrevivir en un mundo hostil, superando peligros mortales, antes de reproducirse y extender los genes que ahora nos conforman. Hay una línea ininterrumpida desde nuestro primer ancestro hasta cada uno de nosotros con innumerables ramificaciones fallidas. Si hiciéramos un cálculo de probabilidades, sería más fácil que nos tocara la lotería varias veces a que hubiéramos llegado a existir. Y, sin embargo, aquí estamos. Sin necesidad de ningún dios.

Alguien podría pensar que lo anterior es la prueba de un milagro divino, que es imposible tanta casualidad. Nada de eso. Es como la lotería: la 
perspectiva científica (matemática, en este caso), nos muestra que dada la gran cantidad de jugadores, la probabilidad de que le toque a alguno es muy cercana a uno. La probabilidad de que le toque a uno en particular sí es casi cero, pero que le toque a alguno de entre todos es casi el evento seguro $^{8}$. ¿La comprensión científica de todo esto resta le resta belleza o valor? Nada de eso, se la incrementa. Comprender los fenómenos naturales como lo que son, como fenómenos naturales, aumentando nuestro conocimiento y disminuyendo la ignorancia, es una forma de placer y satisfacción de la que solo nosotros los humanos podemos disfrutar. En la misma línea, Richard Dawkins expresa la misma idea en una de sus mejores obras y cuyo título apunta a lo mismo: Destejiendo el arco iris (2012).

No somos solo un cerebro o una máquina de reproducción de genes, como a veces parece que dice la ciencia. Cada uno de nosotros es un ser único y especial solamente por haber llegado a existir y tener los genes que tiene y vivir en el ambiente que vive. Cada uno puede comprender el mundo que le rodea, maravillarse ante él, y compartirlo con los demás, emocionarse (empatizar) con los otros y hacer que sea lo más bello y agradable posible en un esfuerzo cooperativo por entenderlo y transformarlo. La vida es maravillosa a pesar de todo, y bien entendida, no hace falta pseudociencia para condimentarla. Eso sí, con un poco de ciencia sabe mucho mejor.

\section{Bibliografía.}

Ariely, Daniel (2013). Las trampas del deseo: Cómo controlar los impulsos irracionales que nos llevan al error. Barcelona: Planeta.

Carmona Campo, Andrés (2013a). "Ciencia, creencias y política", El Escéptico, no 37, agosto-diciembre, pp. 24-29. Accesible en internet: www.escepticos.es/repositorio/elesceptico/articulos_pdf/ee_37/ee_37_ la_ciencia_en_los_limites_y_los_limites_de_la_cienciaciencia_creencias_y_politica.pdf

\footnotetext{
8 Otra forma de verlo es pedir a un público grande que se ponga en pie y lance una moneda al aire varias veces consecutivas. Después se pide que quienes obtengan cara lancen otra vez y quienes obtengan cruz que se sienten y dejen de hacerlo. Tras varios lanzamientos, al final habrá alguien de entre todos que obtenga cara todas las veces. Lo que ha ocurrido no es que esa persona sea especialmente afortunada ni ningún milagro: es simple probabilidad en acción. Lo extraño sería señalar a uno del público en concreto y que lanzara la moneda y obtuviera siempre cara.
}

Claridades. Revista de filosofía 7 (2015) 
Carmona Campo, Andrés (2013b). "Izquierda posmoderna, ciencia y pseudociencia”, El Escéptico, no 38, primavera-verano, pp. 25-32. Accesible en internet:

www.escepticos.es/repositorio/elesceptico/articulos_pdf/ee_38/ee_38_izquierda_posmoderna_ciencia_ y_pseudociencia.pdf

Dawkins, Richard (2002). El gen egoista: Las bases biológicas de nuestra conducta. Barcelona: Salvat.

Dawkins, Richard (2012). Destejiendo el arco iris. Barcelona: Tusquets.

Delgado, Eparquio. (2014). Los libros de autoayuda, ivaya timo! Pamplona: Laetoli.

Ehrenreich, Barbara (2012). Sonrie o muere: La trampa del pensamiento positivo. Madrid: Turner.

Gilbert, Daniel (2006). Tropezar con la felicidad. Barcelona: Destino.

Haidt, Jonathan (2012). "El perro emocional y su cola racional", en Cortina, Adela (ed). Guia Comares de Neurofilosofía Práctica. Granada: Comares.

Kahneman, Daniel (2013). Pensar rápido, pensar despacio. Barcelona: Debolsillo.

Pinker, Steven. (2008). Cómo funciona la mente. Barcelona: Destino.

Sanz, Víctor-Javier (2010). La homeopatía jvaya timo!, Pamplona: Laetoli.

Sokal, Alan (2009), Más allá de las imposturas intelectuales. Barcelona: Paidós.

Wilson, E. O. (1991). Sobre la naturaleza humana. Fondo de Cultura Económica de España.

Wiseman, Richard (2008). Rarología: La curiosa ciencia de la vida cotidiana. Madrid: Temas de Hoy.

Wiseman, Richard (2011). ¿Esto es paranormal?: Por qué creemos en lo imposible. Barcelona: RBA.

ANDRÉS CARMONA CAMPO es licenciado en filosofía y en antropología social y cultural, profesor de filosofía en el IES Hermógenes Rodríguez y colaborador en el blog Filosofía en la Red: www.filosofiaenlared.com.

Lineas de investigación:

Filosofía de la ciencia, la política y la religión.

Publicaciones recientes:

"Irquierda posmoderna, ciencia y psendociencia", El escéptico, 38 (2013), pp.25-32.

Dirección electrónica: andrescarmonacampo@yahoo.es

Claridades. Revista de filosofía 7 (2015) 